\title{
NITROGÊNIO RESIDUAL DA SOJA NA PRODUTIVIDADE DE GRAMÍNEAS E DO ALGODÃO
}

MASCARENHAS, Hipólito A. A..$^{1 \cdot, 2}$ ESTEVES, José Antonio de Fátima ${ }^{2}$ WUTKE, Elaine Bahia ${ }^{2}$ LEÃO, Paulo César da $\mathrm{Luz}^{3}$

RESUMO: Estudou-se a influência do nitrogênio com a utilização da inoculação de Bradyrhizobium e soja. A eficiência da inoculação é dependente principalmente de uma boa condição com relação à acidez e a fertilidade do solo. Nas décadas de 1970 a 90, foram realizados diversos estudos com relação ao cultivo da soja em sistemas de rotação com diversas gramíneas (arroz, milho, sorgo, trigo, cana-de-açúcar e também o algodão). Esses estudos mostraram que além da preservação do ambiente, o efeito residual do nitrogênio fixado pelo cultivo da soja e de seus restos culturais, permite a substituição parcial ou total da adubação nitrogenada na cultura seguinte, obtendo-se a otimização da produtividade e a redução parcial dos custos de produção.

Palavras-chave: Soja. Inoculante. Nitrogênio. Produção.

\section{SOYBEAN RESIDUES AS A SOURCE OF SUPPLY OF NITROGEN: TO GRAMINEOUS AND COTTON}

SUMMARY: A study wa made on the influence of nitrogen with the utlization of inoculant of Bradyehizobium in soybeans. The efficiency of the inoculation depends pirncipally on good conditions relative to acidity and soil fertility. During the decades 1970 to 90 , were realized different studies with soybeans in rotation with gramineous (rice, corn, sorghum, wheat, sugarcane and cotton). By these studies the enviroment was preserved, and the residual nitrogen fixed by soybeans and the rest of the culture, permitting the substitution parcially or totally the nitrogen fertilization to the following crop, in this way obtaining the optimum productivity and reduction partially of the cost of production.

Keywords: Soybeans. Inoculant. Nitrogen. Production.

\section{INTRODUÇÃO}

O nitrogênio é um dos nutrientes requeridos em quantidades relativamente grandes pelas culturas agrícolas sendo, portanto, considerado um macronutriente. Aproximadamente $78 \%$ do ar atmosférico é constituído por esse elemento, mas sob uma forma não diretamente assimilável pelas plantas. Plantas da família das Leguminosas (Fabaceae), entretanto, e somente elas, são capazes de absorvê-lo por meio de nódulos formados nas raízes ( Figura 1),

\footnotetext{
${ }^{1}$ Pesquisador científico aposentado, servidor voluntário.

${ }^{2}$ Pesquisador científico, Instituto Agronômico - IAC; Av. Barão de Itapura, 1.481, 13075-630 Campinas, SP; hipólito@iac.sp.gov.br; jafesteves@iac.sp.gov.br; ebwutke@iac.sp.gov.br

${ }^{3}$ Assistente de Planejamento CATI/EDR Orlãndia-SP; pauloleao@ feituverava.com.br
} 
os quais são espontaneamente desprendidos no solo. A fixação do nitrogênio ocorre graças à simbiose estabelecida pela planta com bactérias do gênero Bradyrhizobium que são adicionadas às sementes, pela inoculação, imediatamente antes da semeadura (PENDLETON; HARTWIG, 1973).

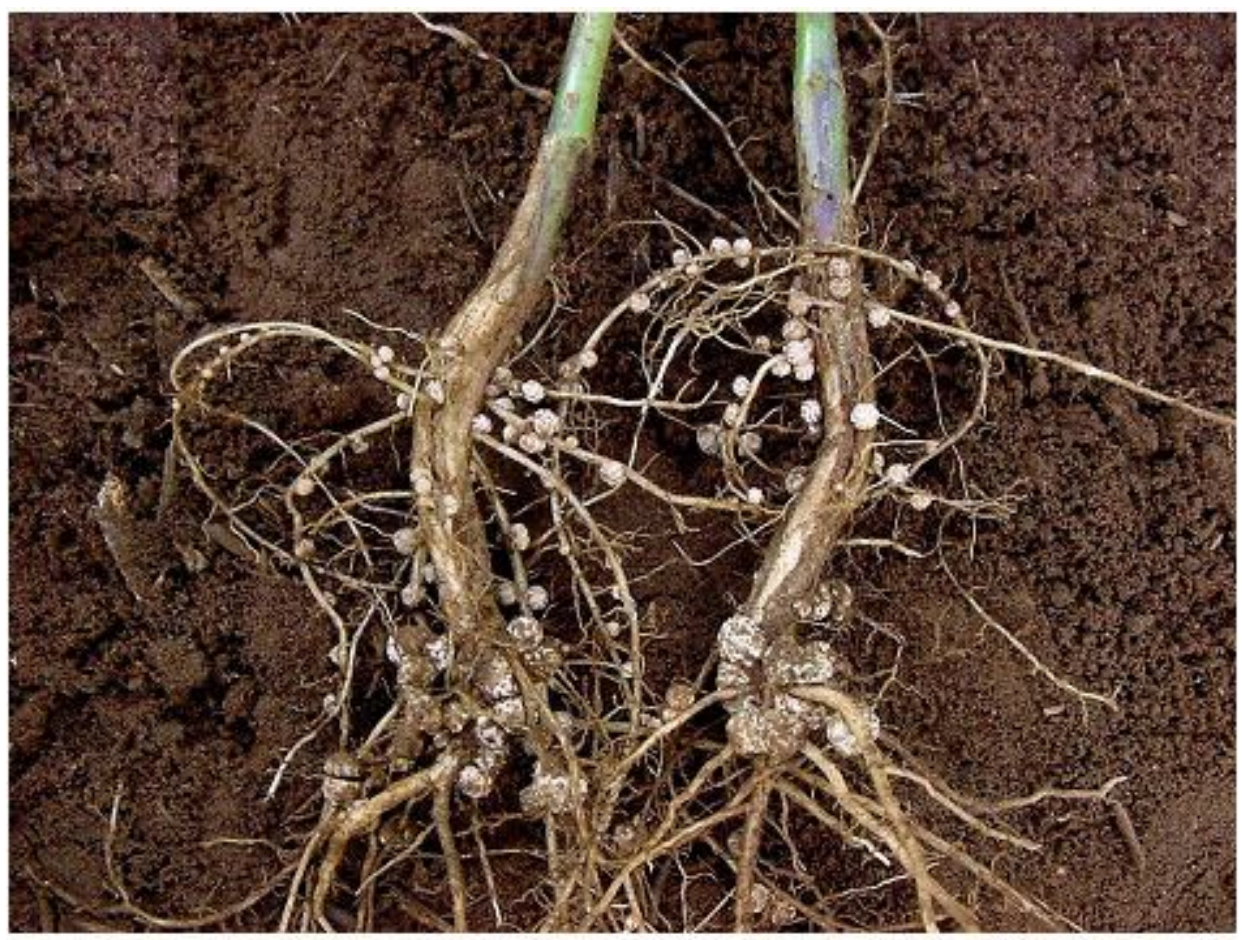

Figura 1. Raízes de soja bem noduladas.

Fonte: Dirceu Gassen.

No caso da soja, a bactéria é da espécie $B$. japonicum, cuja eficácia é de tal magnitude que a adubação nitrogenada pode até mesmo ser dispensada pelo agricultor. $\mathrm{O}$ mesmo não ocorre com espécies cultivadas não-leguminosas, como as gramíneas: arroz, milho, sorgo, trigo e cana-de-açúcar, além do algodão (Malvaceae), nas quais se faz necessária normalmente, a aplicação de adubação nitrogenada.

A simbiose da soja com o Bradyrhizobium específico, pode proporcionar uma fixação de 100 a $160 \mathrm{~kg}$ de nitrogênio por hectare de solo cultivado (VEST et al.1973). Em termos de suprimento de nitrogênio, ocorre geralmente, efeito benéfico na sucessão de uma leguminosa por outras culturas não leguminosas. No entanto, para que esses efeitos possam ser maximizados, faz-se necessária a inoculação artificial prévia das sementes de soja com a bactéria específica. Também, o solo precisa estar adequadamente corrigido pela calagem, para que a saturação por bases trocáveis (V\%) esteja num nível satisfatório, ou seja, de $60 \%$ a 70\%, e também com teores adequados de cálcio e magnésio (RAIJ et al, 1997).

Para se obter uma nodulação adequada, além da correção da acidez do solo, é 
necessária a adequação dos teores de fósforo e potássio, sendo que, no caso do fósforo, o fertilizante fosfatado, particularmente aplicado na forma de superfosfato simples, além do fósforo, contém 13\% de enxofre em sua formulação, sendo este um elemento importante para que ocorra o processo de simbiose (Figura 2). Logo após a inoculação das sementes, deve-se aplicar também o molibdênio, micronutriente que tem participação importante no processo de fixação do nitrogênio. Deve-se atentar para o poder germinativo das sementes que deverá estar entre $80 \%$ a $100 \%$. No entanto, a presença de nódulos em uma raiz de leguminosa não significa um suprimento adequado de $\mathrm{N}$ à planta. Em relação à fixação simbiótica, os nódulos podem ou não ser eficientes, podendo estar havendo muita, pouca ou nenhuma fixação de N.

Quando eficientes, os nódulos são bem desenvolvidos e, em corte transversal, apresentam coloração interna vermelha intensa devido à presença de uma forma de hemoglobina, denominada leghemoglobina (Figura 3) (VEST et al. 1973). A Figura 4 mostra uma planta de soja IAC-Foscarin-31, com vagens bem distribuídas e raízes desenvolvidas em profundidade, indicativo de níveis adequados de calagem e adubação, já que a produtividade obtida foi de $4.000 \mathrm{~kg} \mathrm{ha}^{-1}$.

$\mathrm{Na}$ atual crise energética e econômica mundial, o custo da produção agrícola tem sido consideravelmente elevado em função do preço dos fertilizantes nitrogenados. A energia despendida para a produção de $50 \mathrm{~kg}$ de fertilizantes desse tipo é equivalente àquela proporcionada para obtenção de cerca de 80 litros de petróleo, quantidade esta superada pela fixação biológica pela soja, segundo estimativa de pesquisadores norte-americanos (ROHWEDER et al., 1977).

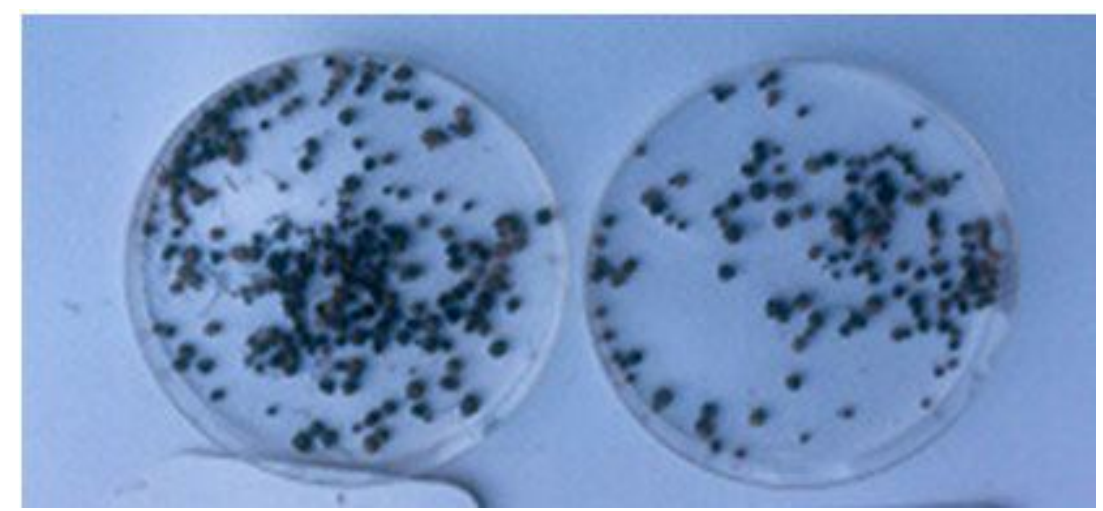

Figura 2. À direita, nodulação obtida em área com deficiência de enxofre e, esquerda, em área devidamente corrigida com sulfato de amônio

Fonte: Hipólito A. A. Mascarenhas 


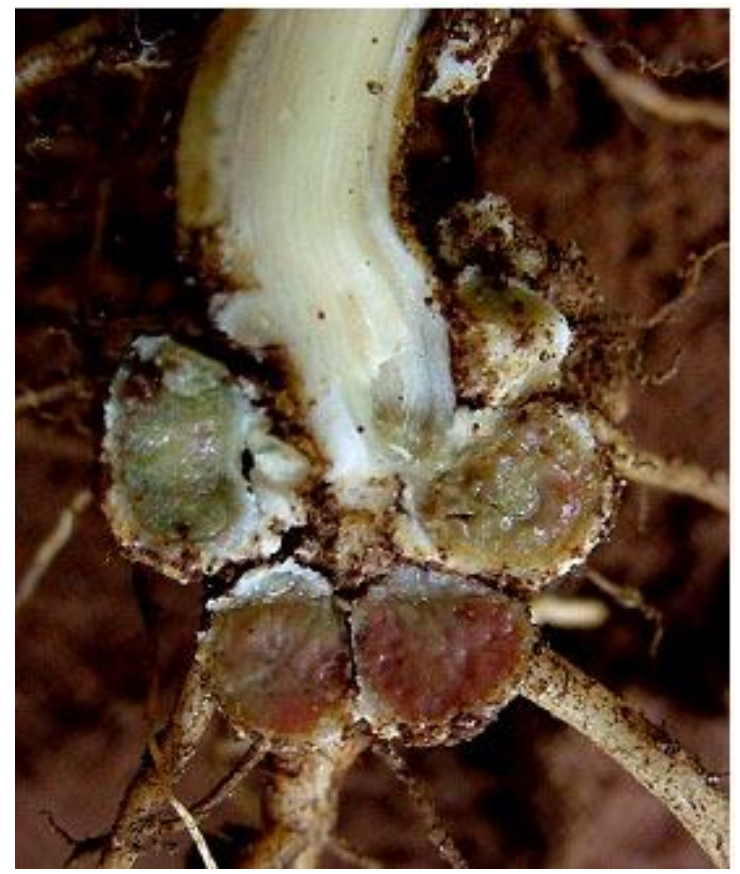

Figura 3. Coloração interna vermelha de nódulo de soja, em corte transversal, indicativa de eficácia na fixação de nitrogênio.

Fonte: Dirceu Gassen

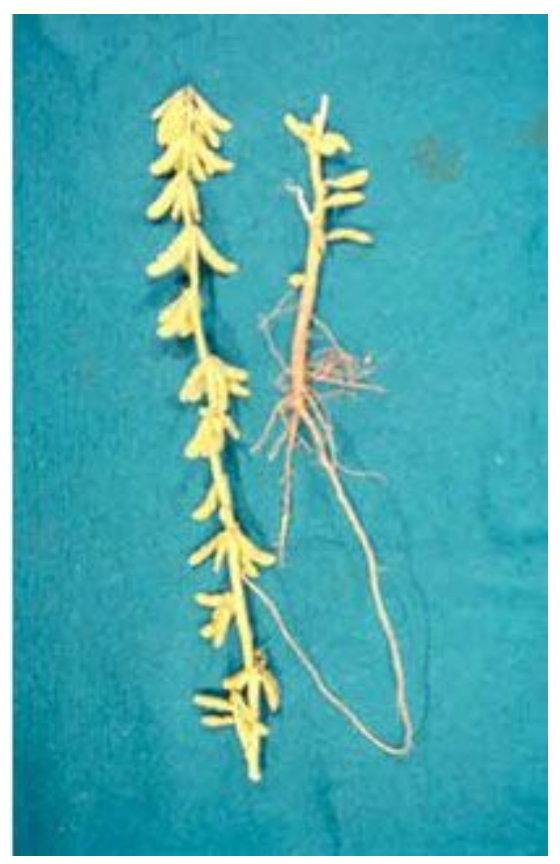

Figura 4. Planta de soja IAC-Foscarin-31, com vagens bem distribuídas e raízes desenvolvidas em profundidade, indicativas de calagem e adubação adequadas.

Fonte: Hipólito A. A. Mascarenhas

Como consequente e relevante contribuição para o agronegócio paulista, particularmente nos anos 70 a 90, no Instituto Agronômico - IAC, sediado em Campinas, SP, foram realizados diversos estudos relacionados à cultura da soja em rotação e, ou sucessão, 
com gramíneas de importância alimentícia e econômica como: arroz, milho, sorgo, trigo, cana-de-açúcar e também algodão, porém, apenas no sistema de preparo convencional do solo. Mais recentemente, entretanto, em relação à produtividade de algumas dessas culturas, não vêm sendo constatadas diferenças entre o sistema convencional e o sistema plantio direto, por exemplo (PAULETTI et al., 2003; SANTOS et al., 2006).

Além da contribuição para a preservação ambiental, as pesquisas realizadas no Instituto Agronômico de Campinas, mostram que o efeito residual do nitrogênio fixado na cultura da soja e nos seus restos culturais pode apresentar uma condição que permita a substituição parcial ou total da adubação nitrogenada na cultura seguinte, garantindo a otimização da produtividade e redução parcial dos custos de produção.

A seguir são apresentados os principais resultados obtidos para gramíneas e algodão, cultivadas no Estado de São Paulo.

ARROZ: Em experimento realizado na cidade de Ribeirão Preto, SP (PEREIRA et al., 1979), em campo de multiplicação de sementes de arroz, cultivar Batatais, após quatro anos consecutivos do cultivo de soja, cv Santa Rosa, obteve-se como resultado para cada quilo de nitrogênio aplicado (Figura 5) a produção de 15,8 kg de arroz com casca. Houve aumento significativo quanto à produtividade apenas na dose de $60 \mathrm{~kg}$ de $\mathrm{N}$ (Tabela $1 \mathrm{e}$ Figura 5).

A utilização de elevadas doses de $\mathrm{N}$ em cobertura favorece o desenvolvimento vegetativo do arroz, o que pode contribuir para o aumento da incidência de brusone, em períodos chuvosos, doença causada pelo fungo Pyricularia grisea, acarretando prejuízos à produtividade. No cultivo do arroz em sucessão à soja, esse problema pode ser controlado, sendo que, esse fator, deve ser considerado no momento da decisão pela aplicação, ou não, de $\mathrm{N}$ em cobertura ou pela adoção da tecnologia descrita acima.

O agricultor Hirofumi Kage, da cidade de Guaíra, SP, baseado nestes estudos, cultivou o arroz anualmente por cinco anos após o cultivo de soja bem adubada. $\mathrm{O}$ arroz que sucedeu à soja não foi adubado e nem foi aplicado nitrogênio em cobertura obtendo-se em média, aproximadamente, $5000 \mathrm{~kg} \mathrm{ha}^{-1}$ de grãos demonstrando a eficiência desse sistema de produção. 
Tabela 1. Produtividades médias de arroz com e sem casca e teores de nitrogênio na parte aérea, em função de cinco doses de nitrogênio. Ribeirão Preto, SP.

\begin{tabular}{cccc}
\hline \multirow{2}{*}{$\begin{array}{c}\text { Doses de } \\
\left(\mathrm{kg} \mathrm{ha}^{-1}\right)\end{array}$} & \multicolumn{2}{c}{ Produção de arroz } & \multirow{2}{*}{$\begin{array}{c}\text { Teor de N } \\
\text { na parte aérea }\end{array}$} \\
\cline { 2 - 3 } & Grãos com casca & Grãos sem casca & $\left(\mathrm{g} \mathrm{kg}^{-1}\right)$ \\
\cline { 2 - 3 } & $---\mathrm{kg} \mathrm{ha}^{-1}------$ & $12,0 \mathrm{c}^{*}$ \\
20 & 4.931 & 3.049 & $15,0 \mathrm{bc}$ \\
40 & 4.538 & 3.153 & $15,3 \mathrm{~b}$ \\
60 & 4.988 & 3.561 & $18,2 \mathrm{ab}$ \\
80 & 5.054 & 3.823 & $21,0 \mathrm{a}$ \\
\hline $\mathrm{F}$ & n.s. & 3.906 & -- \\
\hline
\end{tabular}

(*) Com letras diferentes há significância pelo teste de Tukey a 5\%.

Fonte: Pereira et al. (1979).

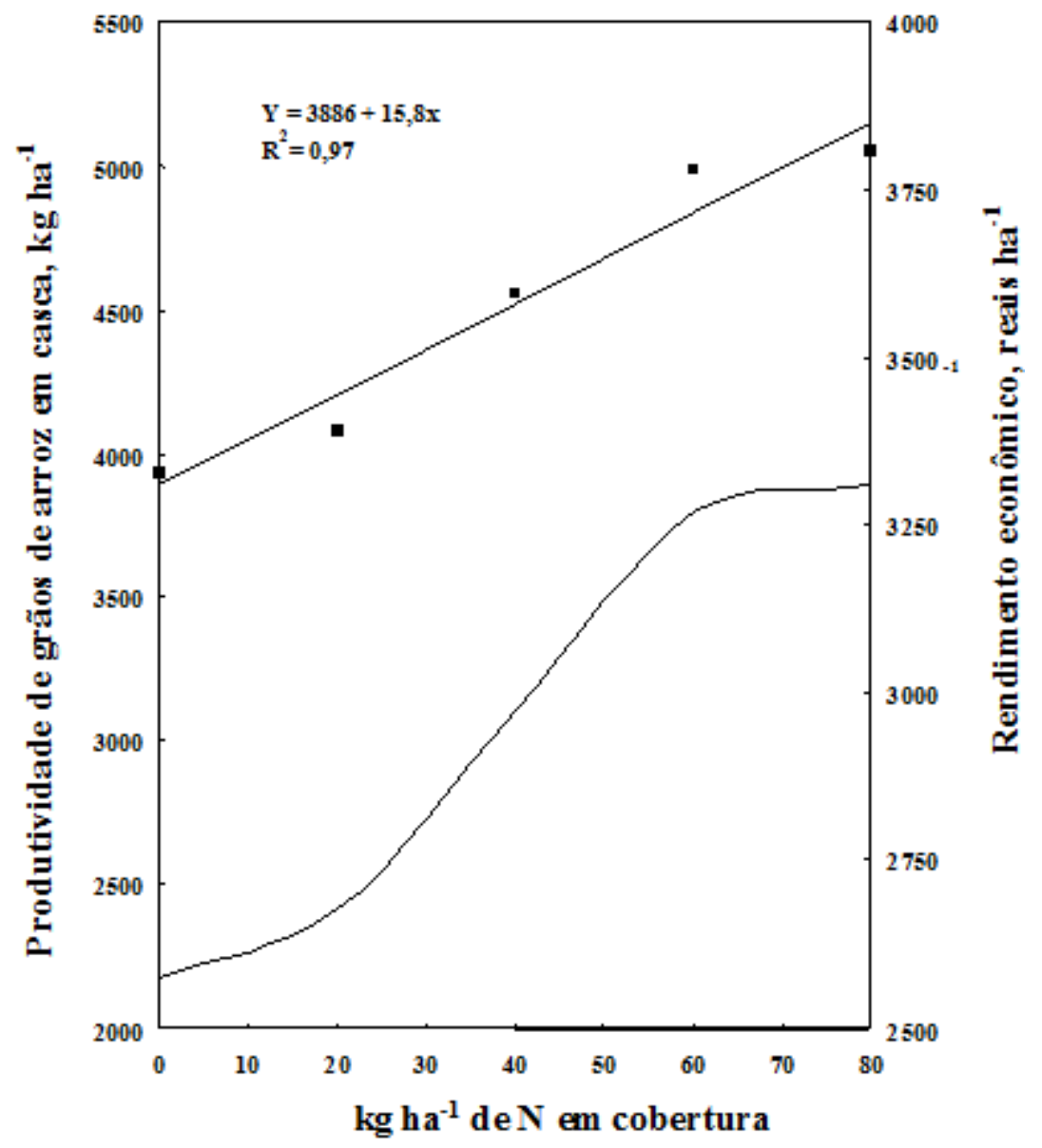

Figura 5. Regressão linear da produtividade média de grãos de arroz com casca para níveis de adubação nitrogenada em cobertura.

Fonte:Pereira et al. (1979).

MILHO: O trabalho de Miranda (1966) mostra o aumento de produtividade do milho com a aplicação de $120 \mathrm{~kg} \mathrm{ha}^{-1}$ de $\mathrm{N}$, com os teores de $\mathrm{P}$ e $\mathrm{K}$ no solo em níveis adequados. 
Em outro estudo realizado na região da Alta Mogiana, SP, em Latossolo Vermelho, em duas áreas: Guaíra I e II, após um e quatro anos consecutivos com cultivo de milho sucedendo à soja, cultivar Santa Rosa, foi obtido aumento médio de $4,35 \mathrm{~kg} \mathrm{ha}^{-1}$ na produção de milho para cada quilo de nitrogênio aplicado, embora os tratamentos não apresentassem diferença estatística entre si. Conforme o aumento no número de anos do cultivo da soja verificou-se uma tendência de aumento na produtividade de grãos de milho. (Tabela 2, Figura 6) (MASCARENHAS et al., 1978).

Tabela 2. Produtividade de grãos de milho em função da aplicação anual de sulfato de amônio, em cobertura, após quatro anos consecutivos de cultivo de soja, cultivar Santa Rosa, em duas áreas de Guaíra, SP.

\begin{tabular}{|c|c|c|c|c|c|}
\hline \multirow{2}{*}{$\begin{array}{c}\text { Doses } \\
\text { de } \mathrm{N} \\
\text { aplicadas em } \\
\text { cobertura }\end{array}$} & \multicolumn{4}{|c|}{ Anos anteriores de cultivo de soja } & \multirow[b]{2}{*}{ Média } \\
\hline & 1 & 2 & 3 & 4 & \\
\hline \multicolumn{6}{|c|}{ Guaíra I } \\
\hline & & & gg ha & & - \\
\hline 0 & 3.599 & 5.326 & 5.397 & 6.397 & 5.180 \\
\hline 20 & 4.216 & 5.162 & 5.775 & 6.395 & 5.387 \\
\hline 40 & 4.160 & 5.549 & 5.403 & 6.868 & 5.495 \\
\hline 60 & 3.845 & 5.483 & 6.166 & 6.283 & 5.444 \\
\hline 80 & 4.970 & 5.243 & 6.041 & 6.483 & 5.684 \\
\hline Média & 4.158 & 5.353 & 5.756 & 6.485 & -- \\
\hline $\mathrm{F}$ & 1,62 n.s. & 1,36n.s. & 1,86n.s. & 0,41 n.s. & -- \\
\hline \multicolumn{6}{|c|}{ Guaíra II } \\
\hline 0 & 4.815 & 3.590 & 4.811 & 5.541 & 4.689 \\
\hline 20 & 4.690 & 4.757 & 4.897 & 5.812 & 5.039 \\
\hline 40 & 4.351 & 3.561 & 5.037 & 5.303 & 4.563 \\
\hline 60 & 5.192 & 4.411 & 5.460 & 5.580 & 5.162 \\
\hline 80 & 4.534 & 4.861 & 5.463 & 5.255 & 5.028 \\
\hline Média & 4.716 & 4.236 & 5.134 & 5.498 & -- \\
\hline $\mathrm{F}$ & 0,72 n.s. & 3,31n.s. & 1,90n.s. & 0,62 n.s. & -- \\
\hline
\end{tabular}

Fonte: Mascarenhas et al. (1978).

O teor de nitrogênio do solo foi uma fonte importante para o suprimento das necessidades do milho, constatado pelos teores foliares de nitrogênio acima do nível suficiente (Gallo et al., 1968; CANTARELLA et al., 1997), em todos os tratamentos e nos quatro anos avaliados (Tabela 3) (MASCARENHAS et al., 1978). Os autores também verificaram teores de nutrientes adequados e crescentes, na ausência da aplicação do 
nitrogênio em cobertura, independentemente do número de anos de cultivo com soja. Dessa forma, fica evidenciado que o nível de suficiência do nitrogênio no solo foi decorrente dos restos culturais da soja, incluindo-se raízes e nódulos, além da utilização de 10 a $16 \mathrm{~kg} \mathrm{ha}^{-1}$ de $\mathrm{N}$, como adubação básica inicial, obtendo-se elevados níveis de produtividade na cultura do milho.

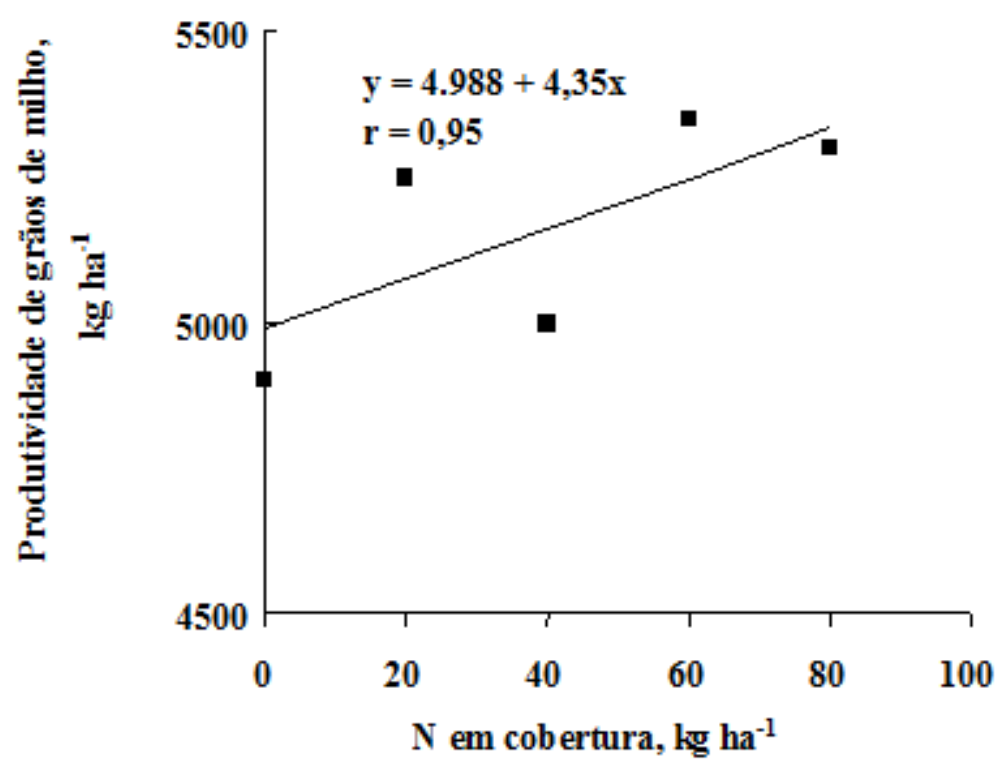

Figura 6. Regressão linear da produção média de grãos de milho para níveis de adubação nitrogenada, aplicada em cobertura, em dois locais de Guaíra, SP.

Fonte: Mascarenhas et al. (1978).

Em ambos os locais, as produtividades médias do milho foram crescentes após os sucessivos anos de cultivos de soja, com acréscimos de $539 \mathrm{~kg} \mathrm{ha}^{-1}$ para cada ano cultivado com soja anteriormente (Figura 7). Esses aumentos de produtividade podem ser atribuídos aos efeitos indiretos obtidos, como melhoria no enraizamento da cultura do milho e na estrutura do solo e maior disponibilidade de N. Embora tenha ocorrido efeito linear na produtividade de grãos do milho, com a aplicação de doses crescentes de N, é evidente a pouca amplitude dessa variação (Figura 6). Com base no rendimento de grãos de milho e, considerando-se o custo do fertilizante nitrogenado, tais doses são antieconômicas (Figura 8). Dados semelhantes foram obtidos por Kamprath et al. (1958), Fleming et al. (1981) e Muzilli et al. (1983). Fleming et al. (1981) e Gallo et al. (1983), mostraram que os restos vegetais de leguminosas não constitui uma fonte duradora de nitrogênio, podendo esse teor residual se esgotar em até 3 anos. 
Tabela 3. Teores de $\mathrm{N}$ nas folhas +4 de milho, devido à aplicação de sulfato de amônio em cobertura e após quatro anos consecutivos de cultivo de soja, em duas áreas em Guaíra, SP.

\begin{tabular}{|c|c|c|c|c|c|}
\hline \multirow{2}{*}{$\begin{array}{c}\text { Doses } \\
\text { de N } \\
\text { aplicadas em } \\
\text { cobertura }\end{array}$} & \multicolumn{4}{|c|}{ Anos anteriores de cultivo com soja } & \multirow[b]{2}{*}{ Média } \\
\hline & 1 & 2 & 3 & 4 & \\
\hline \multicolumn{6}{|c|}{ Guaíra I } \\
\hline $\mathrm{kg} \mathrm{ha}^{-1}$ & 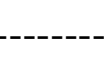 & - & $\mathrm{kg}^{-1}$ & & - \\
\hline 0 & 30,8 & 32,0 & 33,6 & 33,6 & 32,5 \\
\hline 20 & 34,6 & 36,2 & 34,0 & 34,0 & 34,7 \\
\hline 40 & 34,2 & 35,0 & 33,8 & 36,0 & 34,8 \\
\hline 60 & 33,4 & 35,8 & 34,8 & 35,4 & 34,4 \\
\hline 80 & 35,8 & 37,8 & 38,2 & 38,0 & 37,4 \\
\hline Média & 33,8 & 35,4 & 34,9 & 35,4 & - \\
\hline \multicolumn{6}{|c|}{ Guaíra II } \\
\hline 0 & 30,0 & 31,2 & 32,8 & 27,6 & 30,4 \\
\hline 20 & 30,8 & 33,2 & 31,6 & 31,8 & 31,9 \\
\hline 40 & 39,2 & 31,6 & 32,2 & 29,0 & 30,5 \\
\hline 60 & 32,8 & 30,4 & 31,6 & 31,0 & 31,5 \\
\hline 80 & 31,2 & 30,4 & 30,0 & 31,8 & 30,8 \\
\hline Média & 30,8 & 31,4 & 31,6 & 30,2 & - \\
\hline
\end{tabular}

Fonte: Mascarenhas et al. (1978).

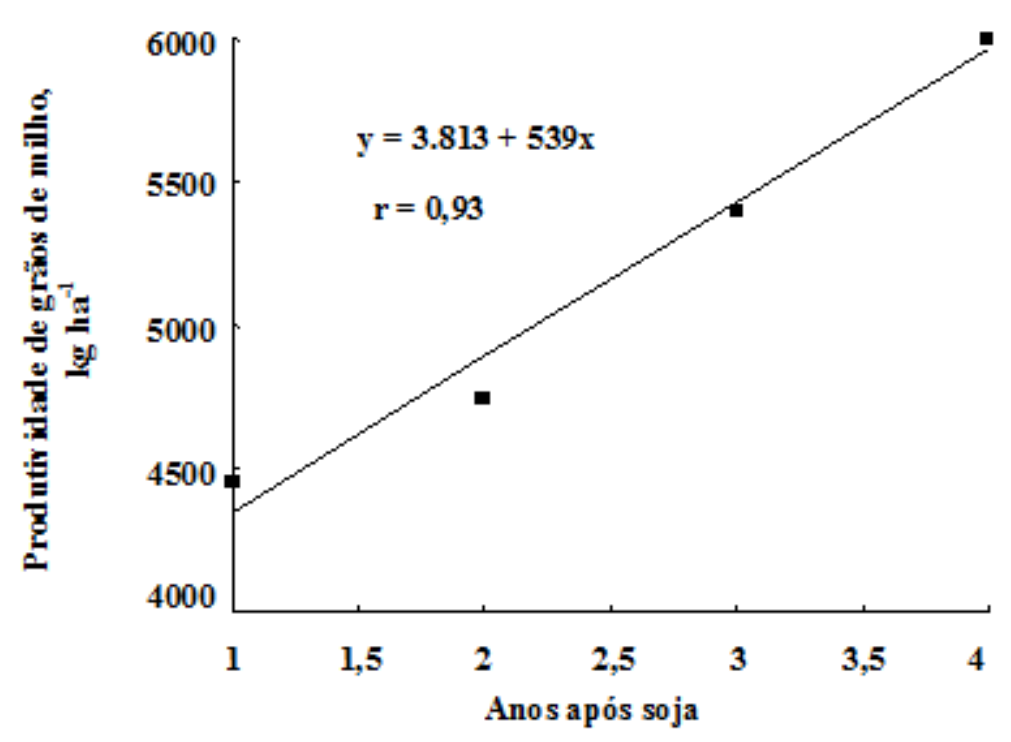

Figura 7. Regressão linear da produtividade média de milho obtida em função de quatro anos de cultivos consecutivos de soja, em dois locais de Guaíra, SP.

Fonte: Mascarenhas et al.. (1978). 
Nos dois solos foi aplicado calcário dolomítico com PRNT de 58\%, para correção da acidez e elevação do índice de saturação por bases para 70\%. Foram realizadas adubações com fósforo e potássio, de acordo com análise de solo e aplicados $40 \mathrm{~kg} \mathrm{ha}^{-1}$ de $\mathrm{N}$, em cobertura, aos 35 dias após semeadura. Em Mococa, nos tratamentos com cultivo de milho após soja, na presença ou na ausência de aplicação de nitrogênio em cobertura, foram constatados acréscimos significativos da ordem de 36 e 29\%, respectivamente, em comparação ao cultivo contínuo do milho, corroborando os resultados obtidos por Mascarenhas et al. (1978). Nos tratamentos de cultivo do milho rotacionado com soja, verificou-se um acréscimo não significativo de $6 \%$ na produtividade de grãos com a aplicação da adubação nitrogenada, evidenciando-se a não necessidade da mesma.

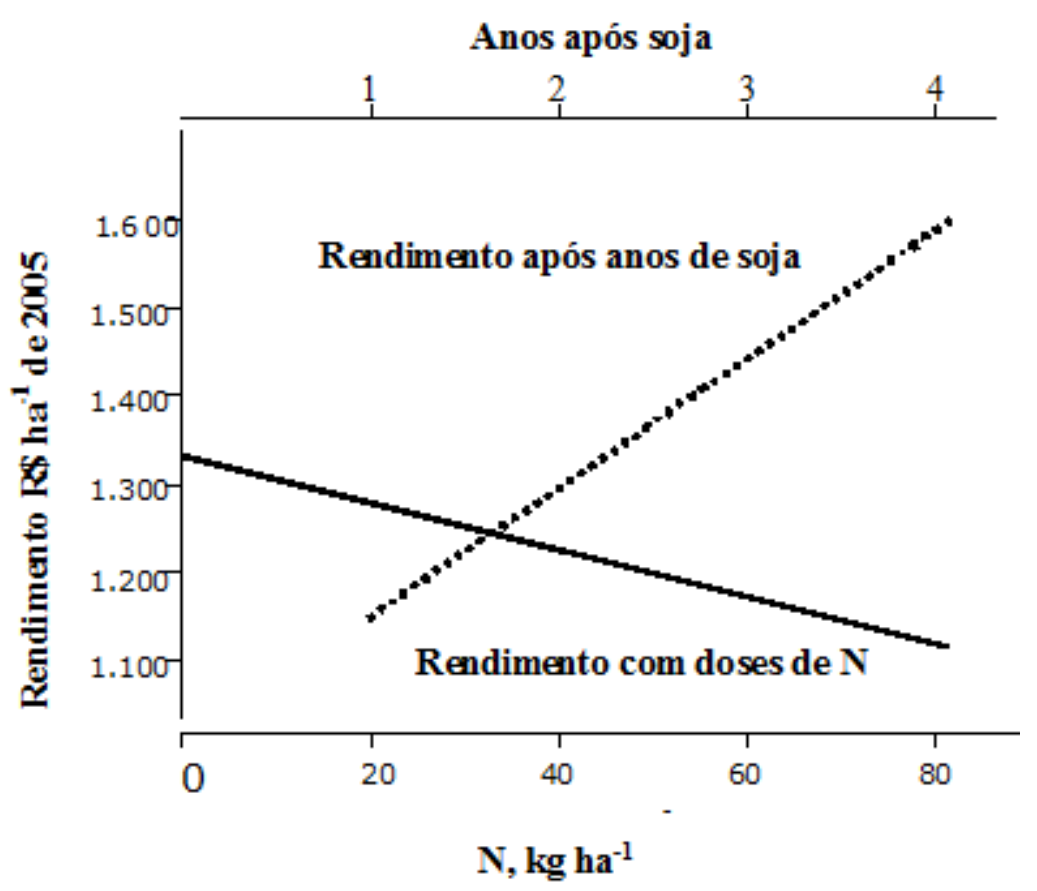

Figura8. Rendimento econômico na cultura de milho, conforme aplicação de doses crescentes de nitrogênio, em cobertura, em quatro anos consecutivos de cultivo de soja.

Fonte: Mascarenhas et al. (1978). 
Tabela 4. Produtividade de grãos de soja e de milho em experimento de rotação de culturas em Mococa e Ribeirão Preto, SP.

\begin{tabular}{|c|c|c|c|c|c|}
\hline \multicolumn{2}{|c|}{ Tratamento de rotação } & \multicolumn{2}{|c|}{ Mococa } & \multicolumn{2}{|c|}{ Ribeirão Preto } \\
\hline $1981 / 1982$ & $1982 / 1983$ & $1981 / 82$ & $1982 / 83$ & $1981 / 82$ & $1982 / 83$ \\
\hline & & ----------. & -------- & -1--- & - \\
\hline Soja & Milho $\mathrm{c} / \mathrm{N}^{1 /}$ & 2455 & $6985 \mathrm{a}$ & 2096 & $3833 \mathrm{a}$ \\
\hline Soja & Milho s/ $\mathrm{N}^{1 /}$ & 2544 & $6613 \mathrm{a}$ & 2083 & $3314 \mathrm{~b}$ \\
\hline Milho c/N & Milho c/N & 4675 & $5130 \mathrm{~b}$ & 4743 & $2604 \mathrm{c}$ \\
\hline
\end{tabular}

SORGO: Gallo et al. (1986) verificaram considerável aumento na produtividade de sorgo, cultivar Contigrão-111, como cultura sucessora à soja, independentemente das doses de $\mathrm{N}$ aplicadas em cobertura, 35 dias após emergência das plantas, na forma de sulfato de amônio, após quatro anos de estudos quanto ao efeito residual de doses de calcário e, também do nitrogênio aplicado em cobertura (Figura 9).

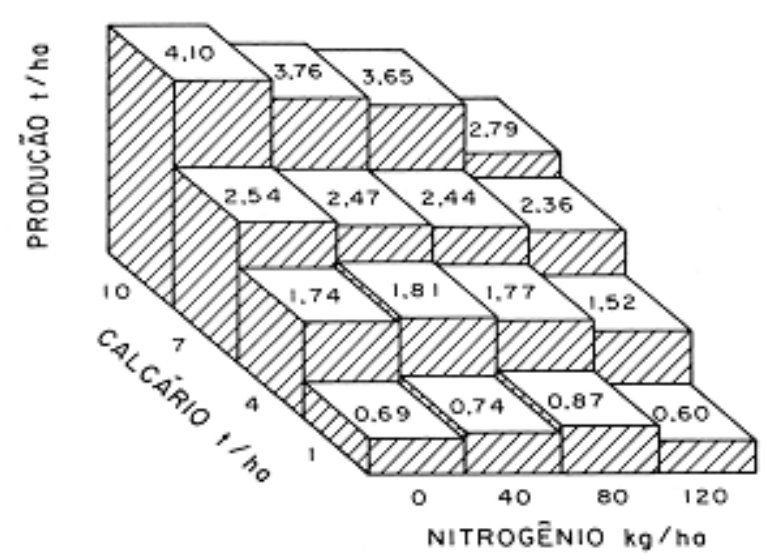

Figura 9. Produtividade média de grãos de sorgo, em $\mathrm{t} \mathrm{ha}^{-1}$, em função de doses de calcário e de nitrogênio em cobertura. Mococa, SP.

Fonte: Gallo et al. (1986). 
Esse aumento está provavelmente associado à elevação da V\% do solo na camada de 0-20 $\mathrm{cm}$ de profundidade, passando de 23 para 67\%, com conseqüente decréscimo da concentração de alumínio nas folhas, diminuindo de 424 para $164 \mathrm{mg} \mathrm{kg}^{-1}$ (Tabela 5). Apesar da aplicação das doses de calcário elevadas, na camada de 0-40 cm de profundidade houve pouca correção da acidez, com a saturação de alumínio sendo muito elevada nos tratamentos com aplicação de menores doses de calcário, razão pela qual as raízes se concentraram na camada mais superficial do solo.

$\mathrm{Na}$ aplicação das doses mais elevadas de calcário, a correção da acidez na camada superficial foi mais adequada do que na subsuperficie, porém ocorreu diminuição da acidez e do teor de alumínio na camada de $20-40 \mathrm{~cm}$ favorecendo um maior aprofundamento do sistema radicular reduzindo-se, portanto, os efeitos do déficit hídrico na produtividade do sorgo.

Tabela 5. Teores de macronutrientes, micronutrientes e de alumínio em folhas de soja; e valores de saturação por bases e de alumínio, em duas profundidades do solo, em função da aplicação de calcário dolomítico. Mococa, SP.

\begin{tabular}{|c|c|c|c|c|c|c|c|c|c|}
\hline \multirow{2}{*}{$\begin{array}{l}\text { Calcário } \\
\text { aplicado }\end{array}$} & \multirow{2}{*}{$\mathrm{K}$} & \multirow{2}{*}{$\mathrm{Ca}$} & \multirow{2}{*}{$\mathrm{Mg}$} & \multirow{2}{*}{$\mathrm{Mn}$} & \multirow{2}{*}{$\mathrm{Al}$} & \multicolumn{2}{|c|}{$\begin{array}{c}\text { Satur. bases no } \\
\text { solo }\end{array}$} & \multicolumn{2}{|c|}{ Satur. Al no solo } \\
\hline & & & & & & $0-20 \mathrm{~cm}$ & $\begin{array}{c}20- \\
40 \mathrm{~cm}\end{array}$ & $0-20 \mathrm{~cm}$ & $20-40 \mathrm{~cm}$ \\
\hline $\mathrm{kg} \mathrm{ha}^{-1}$ & \multicolumn{3}{|c|}{$\begin{array}{c}-\mathrm{-o} \\
-\end{array}$} & \multicolumn{2}{|c|}{---- $\mathrm{mg} \mathrm{kg}^{-1}$} & & ------ & --- & ----- \\
\hline 1 & 13,3 & 4,6 & 1,9 & 65,6 & 424 & 23 & 10 & 59 & 71 \\
\hline 4 & 14,3 & 4,7 & 2,8 & 62,8 & 300 & 37 & 15 & 33 & 61 \\
\hline 7 & 13,2 & 5,0 & 3,6 & 49,8 & 224 & 54 & 21 & 0 & 35 \\
\hline 10 & 13,7 & 4,8 & 4,0 & 43,7 & 164 & 67 & 31 & 0 & 36 \\
\hline
\end{tabular}

Fonte: Gallo et al. (1986).

Houve efeito marcante da calagem na produtividade, mas sem efeito significativo do nitrogênio para cada dose de calcário, sendo este, inclusive, até depressivo, principalmente nas doses mais elevadas do corretivo (Figura 9). Verificou-se aumento linear da concentração de nitrogênio nas folhas em função da adubação nitrogenada, independentemente das doses de calcário (Figura 10).

No tratamento sem aplicação de nitrogênio em cobertura, houve considerável aumento na concentração de nitrogênio nas folhas devido à calagem, provavelmente em função do maior desenvolvimento radicular e, sobretudo, da maior disponibilidade dos nutrientes, 
proporcionada pelos restos culturais da soja cultivada anteriormente por três anos. Deve-se salientar que, na ausência de outras limitações, o nível de 3\% de nitrogênio nas folhas é adequado para que se obtenham produtividades satisfatórias (Hiroce et al., 1981; Cantarella et al., 1997). Para se atingir esse nível de $\mathrm{N}$ nas folhas, foi necessário aplicar $100 \mathrm{~kg} \mathrm{ha}^{-1} \mathrm{de}$ nitrogênio nas parcelas onde foi aplicada a dose de $1 \mathrm{t} \mathrm{ha}{ }^{-1}$ de calcário; $85 \mathrm{~kg} \mathrm{ha}^{-1}$ de nitrogênio em relação à dose de $4 \mathrm{t} \mathrm{ha}^{-1}$ e menos de $30 \mathrm{~kg} \mathrm{ha}^{-1}$ de nitrogênio na aplicação das doses mais elevadas, 7 e $10 \mathrm{t} \mathrm{ha}^{-1}$ (Figura 10). Esses índices são indicadores adequados da economia que pode ser obtida utilizando-se a soja no sistema a rotação de culturas, com o aproveitamento dos resíduos do cultivo da soja como fonte residual de nitrogênio para o sorgo, principalmente se este for cultivado na sequência do cultivo da leguminosa.

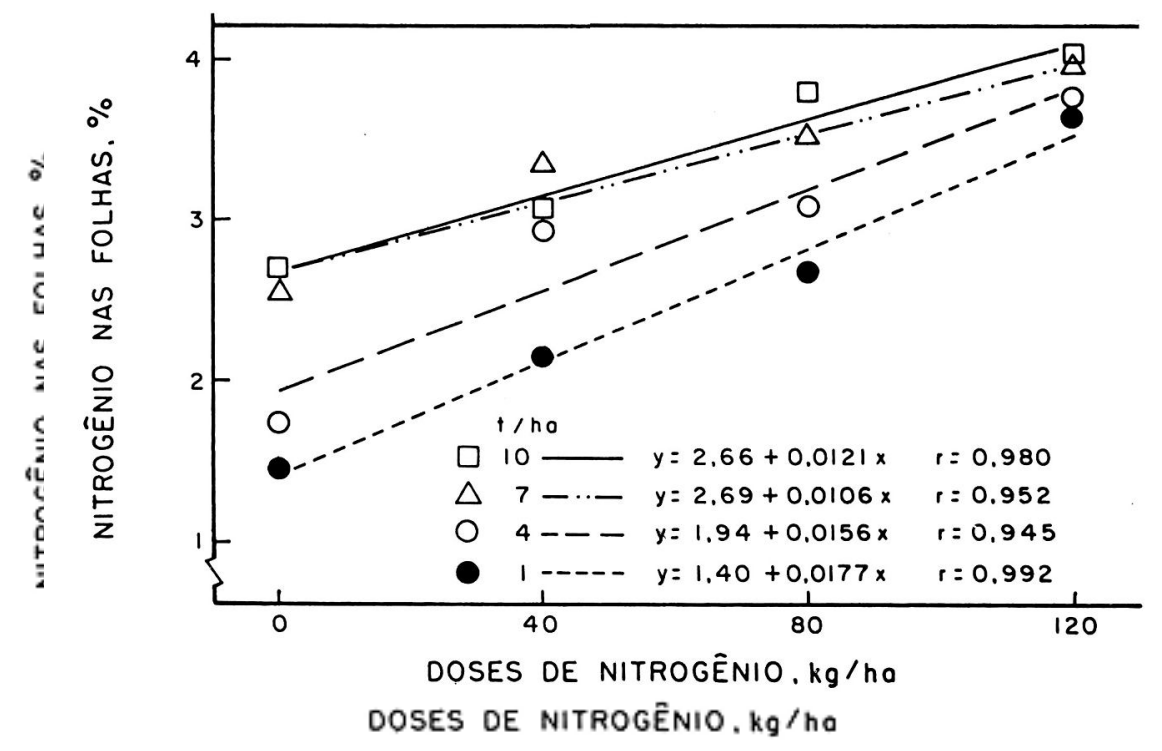

Figura 10. Teor foliar de nitrogênio em folhas de sorgo em função da aplicação de doses de adubo nitrogenado. Mococa, SP.

Fonte: Gallo et al. (1986).

TRIGO: Em experimentação com a cultura de trigo, cultivar IAC-5, em Campinas, SP, (OLIVEIRA et al., 1979) utilizaram uma área destinada, no ano anterior, para a multiplicação de sementes de duas linhagens de soja, distintas quanto à capacidade de nodulação. As sementes da linhagem nodulante (D7193.30) haviam sido inoculadas com estirpes de B. japonicum e as da linhagem não nodulante (D7193.31) adubadas em cobertura, 35 dias após a emergência, com $50 \mathrm{~kg} \mathrm{ha}^{-1}$ de $\mathrm{N}$, na forma de sulfato de amônio. 
Posteriormente, após a colheita da soja, o solo foi revolvido para serem incorporados os restos culturais, aplicando-se no sulco de semeadura do trigo, $60 \mathrm{~kg} \mathrm{ha}^{-1}$ de $\mathrm{P}_{2} \mathrm{O}_{5}$ na forma de superfosfato simples.

Os autores constataram que a produtividade do trigo foi $30 \%$ mais elevada na área anteriormente cultivada com a soja nodulante (D7193.30), devido, sobretudo, ao aumento do teor de nitrogênio no solo (Tabela 6). Essa elevação na produtividade do trigo esta diretamente relacionada ao aumento do teor de nitrogênio na parte aérea das plantas, resultando também em maior teor de proteína e de $\mathrm{N}$ nas sementes, ressaltando-se assim o benefício da inoculação da soja no sistema de rotação (OLIVEIRA et al., 1979).

Tabela 6. Produtividade de trigo cultivar IAC-5 e teores de nitrogênio na parte aérea, e de proteína e nitrogênio nas sementes. Campinas, SP.

\begin{tabular}{ccccc}
\hline $\begin{array}{c}\text { Linhagem de } \\
\text { soja }\end{array}$ & Produtividade & $\begin{array}{c}\text { Teor de N } \\
\text { na parte aérea }\end{array}$ & $\begin{array}{c}\text { Proteína } \\
\text { na semente }\end{array}$ & $\begin{array}{c}\text { N nas } \\
\text { sementes }\end{array}$ \\
\cline { 2 - 5 } & $\mathrm{kg} \mathrm{ha}^{-1}$ & $\%$ & $\%$ & $\mathrm{~kg} \mathrm{ha}^{-1}$ \\
\hline $\begin{array}{c}\text { D71.93.30 } \\
\text { (Soja nodulante) } \\
\text { D71.93.31 }\end{array}$ & 1.974 & 1,54 & 15,34 & 53 \\
(Soja nodulante) & 1.529 & 1,32 & 11,29 & 30 \\
\hline
\end{tabular}

Fonte: Oliveira et al. (1979).

De 168 experimentos desenvolvidos na cultura do trigo em condições de campo, por dois anos, nos municípios de Maracaí, Assis e Cruzália, SP, Camargo et al. (1990) obtiveram respostas positivas quanto a produtividade com a aplicação de doses crescentes de nitrogênio em apenas 34 deles, irrigados por aspersão e em 67, em condições de sequeiro. Nos demais, não foram verificados efeitos para produtividade, pelo fato dos mesmos terem sido instalados em áreas anteriormente cultivadas com soja (Figura 11), evidenciando-se, novamente, a não necessidade de se realizar adubação nitrogenada em trigo quando cultivado sucedendo essa leguminosa. 


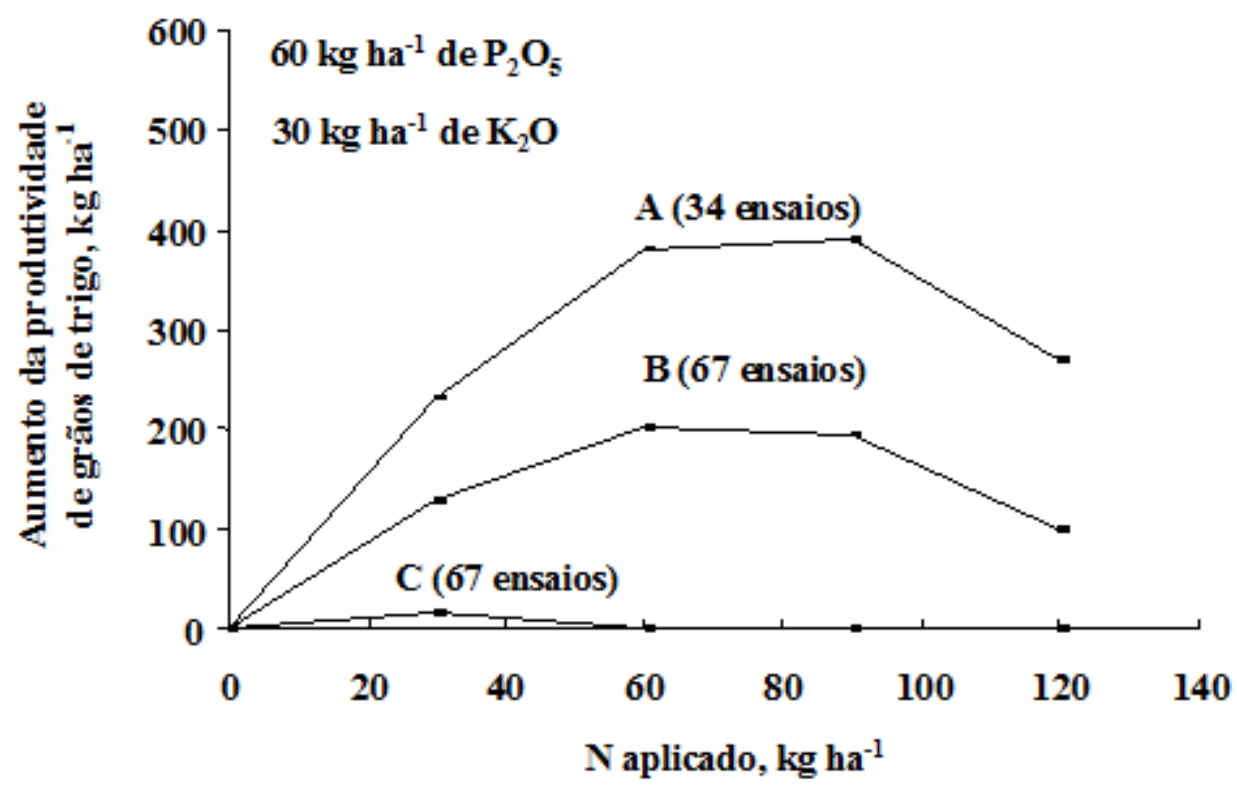

Figura 11. Curvas de resposta de produtividade de grãos de trigo à adubação nitrogenada, em três condições de cultivo: irrigado por aspersão (A); sequeiro (B) e sequeiro após a cultura de soja (C).

Fonte: Camargo et al. (1990).

CANA-DE-AÇÚCAR: Em Orlândia, SP, Mascarenhas et al. (1994) cultivando por dois e três anos, em duas áreas distintas, cana-de-açúcar em sistema de sucessão de culturas com a soja, cultivar IAC-Foscarin-31, avaliaram o efeito dos tratamentos: pousio, pousio $+\mathrm{N}$ na cana (40 kg ha ${ }^{-1}$ de $\mathrm{N}$ em cobertura) e cultivo de soja antecedendo a cana. $\mathrm{O}$ rendimento médio de cana-planta na área cultivada por 3 anos foi respectivamente de 132 e $128 \mathrm{t} \mathrm{ha}^{-1}$ nos tratamentos pousio + $\mathrm{N}$ e após soja, não havendo diferenças estatísticas entre ambos, tendência constatada também para o rendimento de açúcar (Tabela 7). Na área cultivada por 2 anos nesse sistema de sucessão, os resultados alcançados foram semelhantes à área cultivada por 3 anos (Tabela 7), ficando demonstrada a não necessidade da aplicação de $\mathrm{N}$ mineral na cultura da cana após a soja. Além disso, o cultivo por dois anos de cana sucedendo a soja apresentou produtividade de cana-planta $\left(26 \mathrm{t} \mathrm{ha}^{-1}\right)$ e de açúcar $\left(3 \mathrm{t} \mathrm{ha}^{-1}\right)$ mais elevadas em relação ao sistema conduzido na área por 3 anos. Assim, na prática, baseando-se nos custos para o cultivo de ambas as culturas, o empresário agrícola deve optar pelo cultivo da cana-deaçúcar após dois anos com a utilização da soja nesse sistema. 
Tabela 7. Média do rendimento de Cana-planta e de açúcar em sistema com cultivo de soja e cana-de-açúcar em sucessão Orlândia, SP.

\begin{tabular}{|c|c|c|}
\hline \multicolumn{3}{|c|}{ *Rendimento de 3 anos de Cana-de-Açúcar sucedendo a soja } \\
\hline Tratamentos & Cana- planta & Açúcar \\
\hline & \multicolumn{2}{|c|}{ - } \\
\hline Pousio & $123 \mathrm{~b}$ & $14,1 \mathrm{~b}$ \\
\hline Pousio + N (40 $\mathrm{kg} \mathrm{ha}^{-1} \mathrm{~N}$ em cobertura) & $132 \mathrm{a}$ & $15,2 \mathrm{a}$ \\
\hline Soja & $128 \mathrm{ab}$ & $14,7 \mathrm{ab}$ \\
\hline \multicolumn{3}{|c|}{ **Rendimento de 2 anos de Cana-de-Açúcar sucedendo a soja } \\
\hline Pousio & $122 \mathrm{c}$ & $14,0 \mathrm{c}$ \\
\hline Pousio $+\mathrm{N}\left(40 \mathrm{~kg} \mathrm{ha}^{-1} \mathrm{~N}\right.$ em cobertura $)$ & $147 \mathrm{~b}$ & $16,9 \mathrm{~b}$ \\
\hline Soja & $154 \mathrm{ab}$ & $17,7 \mathrm{ab}$ \\
\hline
\end{tabular}

Valores seguidos de mesmas letras, na mesma coluna, não são diferentes estatisticamente pelo teste de Duncan ao nível de 5\%. * 1984/85/; 1985/86; 1986/87 ** 1986/87; 1987/88

Fonte: Mascarenhas et al. (1994)

ALGODÃO: em estudo de Pereira et al. (1988) quanto ao efeito da adubação nitrogenada, aplicada em cobertura, no cultivo contínuo do algodão, cultivar IAC-22, em rotação com soja, cultivar IAC-Foscarin-31, em Mococa e Ribeirão Preto, SP, as produtividades de grãos de soja e de algodão foram consideradas adequadas (Tabela 8). Em ambas as localidades foi aplicado calcário dolomítico, com PRNT de 58\% para correção da acidez do solo e elevação do índice de saturação por bases para 70\%, e também adubação com fósforo e potássio, de acordo com a necessidade, assim como aplicação de $40 \mathrm{~kg} \mathrm{ha}^{-1}$ de $\mathrm{N}$, em cobertura, na cultura do algodão, 35 dias após a semeadura.

Tabela 8. Produtividade de grãos de soja 'IAC-Foscarin-31' e de algodão 'IAC-22' em experimento de rotação de culturas em Mococa e Ribeirão Preto, SP.

\begin{tabular}{|c|c|c|c|c|c|}
\hline \multicolumn{2}{|c|}{ Tratamento de rotação } & \multicolumn{2}{|c|}{ Mococa } & \multicolumn{2}{|c|}{ Ribeirão Preto } \\
\hline $1981 / 1982$ & $1982 / 1983$ & $1981 / 82$ & $1982 / 83$ & $1981 / 82$ & $1982 / 83$ \\
\hline & & \multicolumn{4}{|c|}{ - } \\
\hline Soja & Algodão c/ $\mathrm{N}^{1 /}$ & 2637 & $2754 \mathrm{a}$ & 2097 & $2007 \mathrm{a}$ \\
\hline Soja & Algodão s/ $\mathrm{N}^{1 /}$ & 2555 & $2627 \mathrm{a}$ & 2407 & $2341 \mathrm{a}$ \\
\hline Algodão c/N & Algodão c/N & 1911 & $2772 \mathrm{a}$ & 2696 & $2082 \mathrm{a}$ \\
\hline
\end{tabular}


Tanto em Mococa como em Ribeirão Preto, não houve diferença significativa quanta a produtividade do algodão após soja, devido aos efeitos de tratamentos. Os restos culturais da soja foram suficientes para o suprimento da necessidade de $\mathrm{N}$ pelo algodão, podendo ser dispensada sua aplicação em cobertura. Em algodão cultivado por dois anos consecutivos com aplicação de adubação nitrogenada, também foi alcançada produtividade similar à obtida quando da rotação da cana com a soja. Na safra 1982/83 houve períodos de veranicos no início de janeiro, acarretando prejuízos à produtividade nos dois locais de cultivo.

\section{CONSIDERAÇÕES FINAIS}

Diante do exposto, constata-se que, apenas com a inclusão da soja em alguns dos sistemas de produção tem-se a possibilidade de diminuição ou até mesmo de não utilização da adubação mineral nitrogenada nas culturas em rotação ou sucessão, podendo-se inclusive conseguir a redução do custo de produção das culturas após a soja. Além da otimização dos rendimentos das culturas sucessoras à soja, existe uma contribuição adicional quanto à preservação ambiental pela redução da utilização de adubos minerais nitrogenados e a consequente possibilidade da diminuição da poluição do solo.

Cabe ressaltar que, inicialmente, os agricultores deverão utilizar esses sistemas de sucessão ou rotação em áreas menores em suas propriedades, podendo adotar tais recomendações agronômicas mediante constatação de resultados favoráveis em mais de uma safra agrícola.

\section{REFERÊNCIAS}

CAMARGO, C.E.O.; FELICIO, J.C.; FERREIRA FILHO, A.W.P; FREITAS, J.G.; PETINELLI JÚNIOR, A. ; RAMOS, V.J.; KANTHACK, R.A.D. Adubação N, P, K e S para cultura do trigo no Estado de São Paulo. Instituto Agronômico: Campinas, 1990. 33p (Boletim Técnico, 129).

CANTARELLA, H.; RAIJ, B. van; CAMARGO, C.E. de O. Cereais. In: RAIJ, B. van et al. (Eds.), Recomendações de adubação e calagem para o Estado de São Paulo, 2.ed. rev. atual., 1997. p.45-47 (Boletim técnico, 100)

FLEMING, A.A.; GIDDENS, J.E.; BEATY, E.R. Corn yields as related to legumes and inorganic nitrogen. Crop Sci.: 21:977-980, 1981.

GALLO, J.R.; HIROCE, R.; MIRANDA, L.T. Análise foliar na nutrição de milho. I. Correlação entre análise foliar e produção. Bragantia, Campinas, v.27, n.1, p.177-186, 1968. 
GALLO, P.B.; MASCARENHAS, H.A.A.; BATAGLIA, O.C.; QUAGGIO, J.A. Interação calagem e adubação nitrogenada na produção de sorgo sobre deficiência hídrica em rotação em soja. Bragantia, Campinas, v.45, n.2, p.231-238, 1986.

GALLO, P.B.; SAWAZAKI, E.; HIROCE, R.; MASCARENHAS, H.A.A. P. Produção de milho afetado pelo nitrogênio mineral e cultivo anterior com soja. Revista Brasileira de Ciência do Solo, Campinas, v.7, n.6, p.149-152, 1983.

HIROCE, R.; SAWAZAKI, E.; POMMER, C.V.; MIRANDA, L.T. Efeito de adubação NPK na produção e na composição mineral de folhas de diferentes cultivares de sorgo e milho.

Revista Brasileira de Ciência do Solo, Campinas, v.5, n.1, p.67-71, 1981.

KAMPRATH, E.J.: CHANDLER, W.V.:KRANTZ, R. Wintercover crops. Their effects on corn yields and soil properties. North Caroline Agri. Expt. Stn., 1958, (B. 129).

MASCARENHAS, H.A.A.; HIROCE, R.; BRAGA, N.R.; MIRANDA, M.A.C.; POMMER, C.V.; SAWASAKI, E. Efeito do nitrogênio residual de soja na produção de milho.

Campinas: Instituto Agronômico, 1978. 16p. (Boletim Técnico, 58).

MASCARENHAS, H.A.A.; TANAKA, R.T.; COSTA, A.A.; ROSA F.V. COSTA, V.F. Efeito residual de leguminosas sobre o rendimento físico e econômico da cana planta. Instituto Agronômico, Campinas, 1994, 15p. (Boletim Científico, 32).

MIRANDA, L.T. de. Resultados da experimentação de adubação e sugestões para a interpretação baseada na análise química do solo In: Cultura e Adubação do Milho. São Paulo: Instituto da Potassa, Experimentação e Pesquisa, 1966. p. 451-472. (Cap. XV).

MUZILLI, O.; OLIVEIRA, E.L.; GERAGE,A.C.; TORNERO, M.T. Adubação nitrogenada em milho no Paraná. Pesquisa Agropecuária Brasileira, Brasília, v.18, n.1, p. 23-27, jan. 1983.

OLIVEIRA, O. F.; FELICIO, J.C.; MASCARENHAS, H.A.A.; HIROCE, R., Efeito de nitrogênio residual da soja na produção de trigo. Bragantia, Campinas, v.38, n.1, p.LVIILIX, 1979. (Nota, 3).

PAULETTI, V.; LIMA, M.R.; BARCIK, C.; BITTENCOURT, A. Rendimento de grãos de milho e soja em uma sucessão cultural de oito anos obre diferentes sistemas de manejo de solo e de culturas. Ciência Rural, Santa Maria, v.10, n.1, p.491-495, 2003.

PENDLETON, J.W.; HARTWIG, E.E. Management Chapter 7. In: Soybeans, Improvement, Production and Uses. Editor B,E. Caldwell. American Society of Agronomy, Madison, Wisconsen, USA, pg. 216-217. 1973.

PEREIRA, J. C. V. N. A; MASCARENHAS, H.A.A ; HIROCE , R.; CAMARGO, O.B.A .Efeito de nitrogênio e de rotação com soja na produção de arroz de sequeiro. Bragantia, Campinas, v.38, n.1, p.LIII-LVI, 1979.

PEREIRA, J.C.V.N.A.; MASCARENHAS, H.A.A.; MARTINS, A.L.M.; BRAGA, M.R.; SAWAZAKI; GALLO, P.B. Efeito de adubação nitrogenada em cobertura no cultivo contínuo do milho e do algodão e em rotação com soja. Revista de Agricultura, Piracicaba, v.63, n.1, p.95-108, 1988. 
RAIJ, B van: CANTARELLA, H. QUAGGIO, J.A.; FURLANI, A.M.C. Recomendação de adubação e calagem para o Estado de São Paulo, Boletim Técnico 100, IAC, 1997, pg14-19.

ROHWEDER, D.A.; SHRADER, W.J.; TEPLETON. W.C. Legumes. Crops and Soil, Madison V.9, № 6, p11-14, 1977.

SANTOS, H.P.; AMBROSI, I.; LHAMBY, J.C.B.; CARMO, C. Rendimento de grãos de soja em função de diferentes sistemas de manejo de cultivo. Ciência Rural, Santa Maria, v.13, n.1, p.21-29, 2006.

VEST, G.; WEBER, D.F.; SLOGER, C. Nodulation and Nitrogen fixation In: Soybeans, Improvement, Production and Uses. Editor B.E. Caldwell. American Society of Agronomy, Madison, Wisconsin, USA. 1973. p.373-382. 
